13,06

\title{
Кристаллизация слоев в гетероструктурах PZT/LNO/Si
}

\author{
(C) А.В. Атанова ${ }^{1}$, О.М. Жигалина ${ }^{1,2}$, Д.Н. Хмеленин ${ }^{1}$, Д.С. Серегин ${ }^{3}$, К.А. Воротилов $^{3}$ \\ ${ }^{1}$ Институт кристаллографии им. А.В. Шубникова РАН, „ФНИЦ „Кристаллография и фротоника“ РАН, \\ Москва, Россия \\ ${ }^{2}$ Московский государственный технический университет им. Н.Э. Баумана, \\ Москва,Россия \\ ${ }^{3}$ МИРЭА - Российский технологический университет, \\ Москва, Россия \\ E-mail: atanova.a@crys.ras.ru
}

Поступила в Редакцию 16 июля 2019 г.

В окончательной редакции 16 июля 2019 г.

Принята к публикации 25 июля 2019 г.

Методами просвечивающей электронной микроскопии исследована микроструктура слоев композиции $\mathrm{Pb}\left(\mathrm{Zr}_{0.52} \mathrm{Ti}_{0.48}\right) \mathrm{O}_{3}-\mathrm{LaNiO}_{3}-\mathrm{Si}$ и тонких пленок $\mathrm{LaNiO}_{3}$, полученных методом химического осаждения из растворов. Выявлено, что поликристаллическая, пористая структура $\mathrm{LaNiO}_{3}$ приводит к нарушению столбчатости структуры цирконата-титаната свинца. Рассмотрено влияние термической обработки на структуру и фазовый состав никелата лантана. Показано, что такие морфологические особенности структуры пленки $\mathrm{LaNiO}_{3}$, как слоистость, пористость и разориентированность, наблюдаются при отжиге с температурой $550^{\circ} \mathrm{C}$ и усугубляется при повышении до $800^{\circ} \mathrm{C}$.

Ключевые слова: тонкие пленки, химическое осаждение из растворов, просвечивающая электронная микроскопия, цирконат-титанат свинца, никелат лантана.

DOI: $10.21883 /$ FTT.2019.12.48575.03ks

\section{1. Введение}

Тонкопленочные гетероструктуры на основе цикроната-титаната свинца $\left(\mathrm{Pb}\left(\mathrm{Zr}_{x} \mathrm{Ti}_{1-x}\right) \mathrm{O}_{3}, \mathrm{PZT}\right)$ являются базовым элементом различных интегрированных сегнетоэлектрических устройств, в частности, энергонезависимых элементов памяти [1,2]. Основным функциональным слоем таких гетероструктур является сегнетоэлектрический слой, заключенный между проводящими пленками (электродами). В качестве материала электродов особенно привлекательным является никелат лантана $\mathrm{LaNiO}_{3}(\mathrm{LNO})$, обладающий псевдокубической перовскитной структурой с близким к PZT параметром решетки. Такой оксид, в отличие от традиционно используемых металлических электродов, проницаем для кислородных вакансий, и потому обеспечивает, например, повышение усталостных свойств элемента сегнетоэлектрической памяти [3]. Особый интерес представляет формирование тонкопленочной композиции $\mathrm{PZT} / \mathrm{LNO} / \mathrm{Si}$ в рамках одного технологического метода - химического осаждения из растворов с изменением в процессе многослойного последовательного нанесения исходных пленкообразующих растворов [4].

Как известно, структура электродов в подобных гетероструктурах непосредственно влияет на формирование сегнетоэлектрического слоя, т. к. электрод является затравочным слоем, обеспечивающим гетерогенный механизм роста и формирование ориентированной столбчатой структуры [2,4]. Несмотря на довольно высокие физические свойства композиций, получаемая структура электрода LNO, представленная в литературе на данный момент, далека от совершенства [5-8]. Процесс кристаллизации требует более детального рассмотрения для выявления и устранения причин структурных несовершенств. При этом представлено только небольшое количество исследований структуры на наноуровне, т.е. методами просвечивающей электронной микроскопии.

Ввиду изложенного выше, в работе представлены структурные исследования композиции $\mathrm{PZT} / \mathrm{LNO} / \mathrm{Si}$ методами просвечивающей электронной микроскопии, а также рассмотрена эволюция структуры при варьировании температуры отжига LNO.

\section{2. Образцы и методы исследования}

Образцы для исследования были изготовлены методом химического осаждения из растворов. Для формирования пленки LNO прекурсор наносили послойно до получения заданной толщины, с проведением сушки и кристаллизации после каждого подслоя. Согласно литературным данным $[5,6]$, оптимальной температурой для кристаллизации LNO является $650-700^{\circ} \mathrm{C}$. В связи с этим, в композиции $\mathrm{PZT} / \mathrm{LNO} / \mathrm{Si}$ для формирования слоя LNO температура отжига составляла $650^{\circ} \mathrm{C}$. Для формирования слоя PZT на слой LNO наносили восемь подслоев прекурсора, каждый подслой подвергали термообработке при температуре $150^{\circ} \mathrm{C}$ и $400^{\circ} \mathrm{C}$, после чего весь объем полученного слоя РZT отжигали при температуре $650^{\circ} \mathrm{C}$. Для визуализации структурной эволюции в процессе термической обработки было из- 
готовлено три образца тонких пленок LNO: LNO-550, LNO-650, LNO-800 с завершающим кристаллизационным отжигом при температурах $T=550,650$ и $800^{\circ} \mathrm{C}$, соответственно.

Полученные композиции исследовали методами просвечивающей электронной микроскопии (ПЭМ) и электронной дифракции с использованием микроскопа FEI Tecnai Osiris при ускоряющем напряжении $200 \mathrm{kV}$. Поперечные сечения композиций для исследования в просвечивающем электронном микроскопе изготавливали с помощью фокусированных ионных пучков в колонне растрового электронного микроскопа FEI Scios.

\section{3. Результаты и обсуждение}

На рис. 1 представлено светлопольное ПЭМизображение структуры композиции $\mathrm{PZT} / \mathrm{LNO} / \mathrm{Si}$. Слой PZT составляет $340 \mathrm{~nm}$ и характеризуется направленным ростом столбчатых зерен от межфазной границы. Толщина зерен составляет $30-90 \mathrm{~nm}$, что в 2-4 раза меньше толщины перовскитных зерен, сформированных на платиновом электроде с ориентацией (111) [4,9]. Слой LNO характеризуется ярко выраженной слоистостью: зерна, кристаллизованные за один технологический цикл, остаются в пределах подслоя и разделены строчками пор. Подобное строение проводящего слоя LNO было обнаружено и в других работах [5-8]. Более подробно структура композиций описана авторами в работе [4].

Выраженная слоистость и пористость LNO требуют отработки технологического процесса, при этом необходимо понимание лежащих в основе кристаллизационных механизмов. В связи с этим, ниже представлены результаты исследования влияния температуры отжига на процессы нуклеации пленки LNO (рис. 2-4).

На рис. 2 представлены светлопольное и темнопольное изображение, а также микроэлектронограмма, полученные от образца LNO-550. Видно, что после отжига при $550^{\circ} \mathrm{C}$ пленка характеризуется высокой дисперсно-

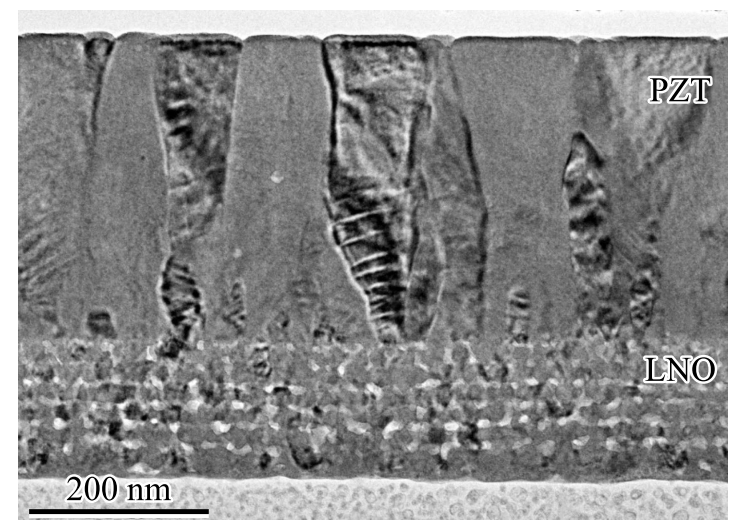

Рис. 1. Светлопольное ПЭМ-изображение микроструктуры композиции $\mathrm{PZT} / \mathrm{LNO} / \mathrm{Si}$.

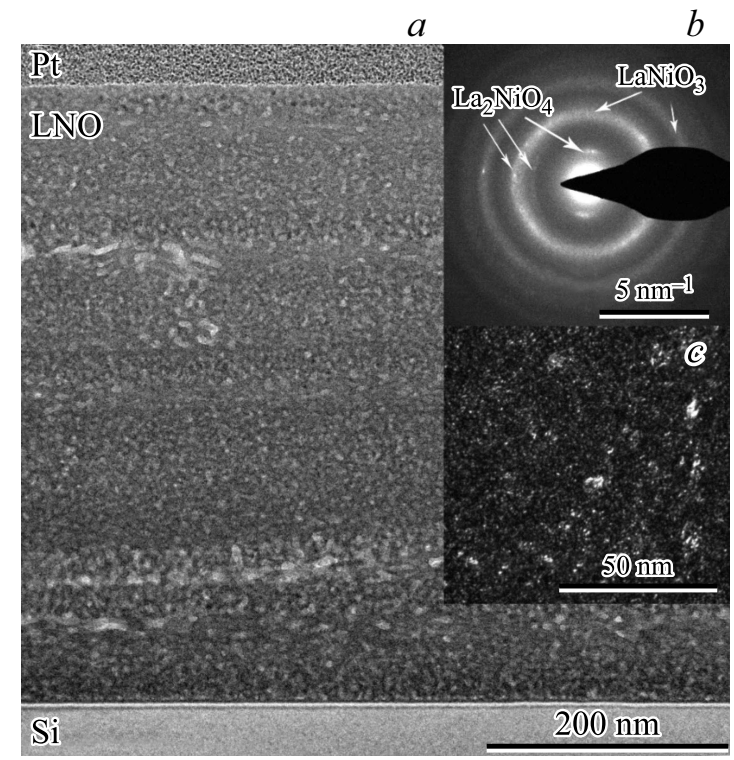

Pис. 2. Структура пленки LNO-550: светлопольное ПЭМ-изображение $(a)$, электронограмма $(b)$ и темнопольное ПЭМ-изображение.

стью структуры и присутствием большого количества аморфной фазы, о чем свидетельствуют размытые, широкие кольца на электронограмме (рис. 2, $b$ ). Наблюдаются рефлексы от крупных кристаллов, но их количество очень мало. Некоторые пики образуют „дуги“, что говорит о присутствии некоторой преобладающей кристаллографической ориентации. Согласно электронограмме, в данном состоянии в пленке могут содержаться две фазы: $\mathrm{LaNiO}_{3}(P m \overline{3} m)$ и $\mathrm{La}_{2} \mathrm{NiO}_{4}(I 4 / m m m)$, однако большая ширина колец и точность электронномикроскопического анализа не позволяют определить более точно фазовый состав. Высокая дисперсность кристаллической фазы отчетливо видна на темнопольном изображении (рис. 2,c). На светлопольном изображении (рис. 2,a) наблюдается большое количество пор, как распределенных по всему объему пленки, так и локализованных на границе раздела слоев. Поры в толще подслоя имеют размер 3-15 nm и обладают преимущественно равноосной формой, а вблизи границ наблюдаются крупные продолговатые пустоты сложной конфигурации, являющиеся результатом слияния более мелких пор.

В сравнении с образцом LNO-550, в структуре образца LNO-650 наблюдается увеличение и пор, и зерен (рис. 3,a). Размер пор варьируется в диапазоне 15-30 nm в направлении, перпендикулярном слоям, а в продольном направлении не ограничивается даже 200 nm, т.к., поры, образующиеся на границе технологических слоев, активно сливаются в полости, переходящие по своему форм-фактору уже в трещины и расслоения. Размер зерен находится в диапазоне $18.8 \pm 7.3 \mathrm{~nm}$. Дифракционная картина имеет более чет- 


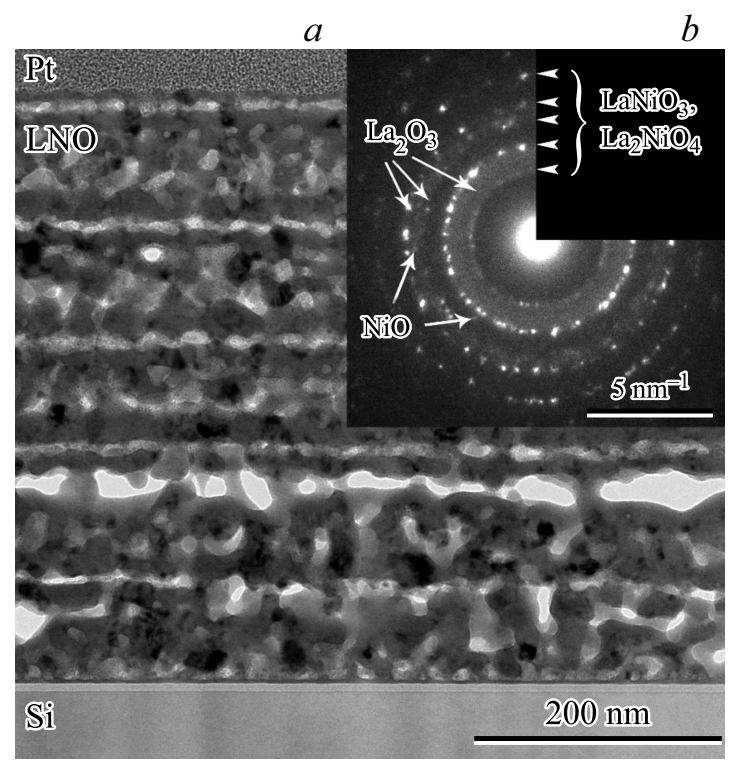

Рис. 3. Светлопольное ПЭМ-изображение структуры пленки LNO-650 $(a)$ и соответствующая электронограмма $(b)$.

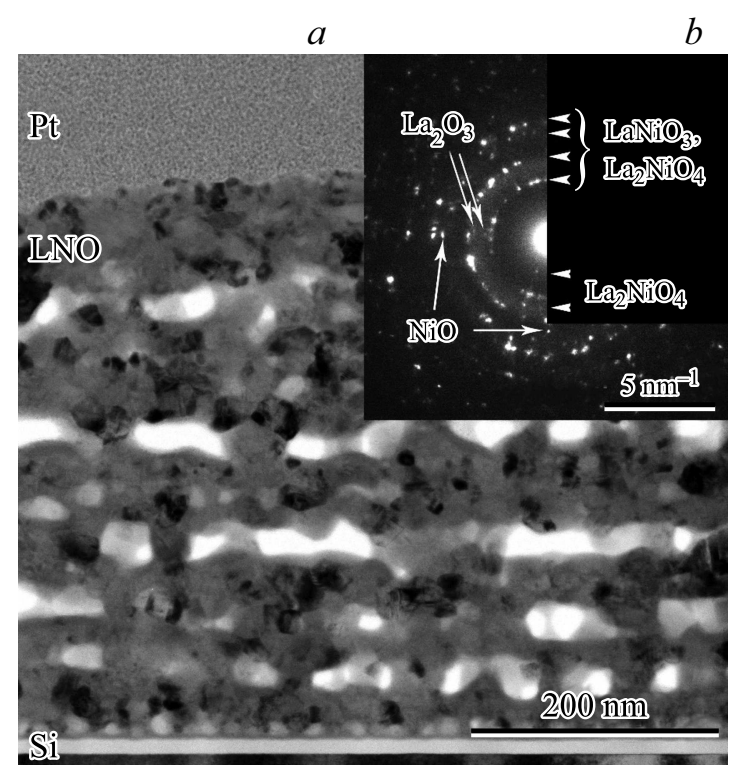

Рис. 4. Светлопольное ПЭМ-изображение структуры пленки LNO-800 $(a)$ и соответствующая электронограмма $(b)$.

кие кольца в сравнении с образцом LNO-550 (рис. 3, b), что говорит об укрупнении кристаллитов, однако гало от аморфной фазы также присутствует на электронограмме. Фазовый анализ показал, что основные кольца, видимые на дифракционной картине, могут принадлежать как фазе $\mathrm{LaNiO}_{3}(P m \overline{3} m)$, так и фазе $\mathrm{La}_{2} \mathrm{NiO}_{4}(I 4 / m m m)$. Кроме того, зафиксированы единичные рефлексы от фаз $\mathrm{NiO}(F m 3 m)$ и $\mathrm{La}_{2} \mathrm{O}_{3}(P \overline{3} m 1)$.

Светлопольное ПЭМ-изображение структуры и микроэлектронограмма образца LNO-800 представлены на рис. 4. В сравнении с образцами LNO-550 и LNO-650, наблюдается дальнейшее увеличение пор и зерен (рис. 4,a). Преобладают продолговатые полости, параллельные подложке, имеющие ширину 20-30 nm и длину от 30 до $200 \mathrm{~nm}$ и более. Небольшие равноосные поры размером менее $30 \mathrm{~nm}$, наблюдаемые при более низких температурах отжига, здесь практически отсутствуют. Размер кристаллитов для данного образца составляет $29.3 \pm 14.2 \mathrm{~nm}$. Проведенный анализ электронограммы (рис. $4, b)$ показал, что состав образца является многофазным и представлен в основном следующими фазами в порядке убывания: $\mathrm{LaNiO}_{3}(P m \overline{3} m), \mathrm{La}_{2} \mathrm{NiO}_{4}($ I4/mmm), $\mathrm{NiO}(F m 3 m), \mathrm{La}_{2} \mathrm{O}_{3}(P \overline{3} m 1)$. В сравнении с электронограммой от образца LNO-650 наблюдается дальнейшее повышение фрагментированности колец. В областях, где присутствовало гало (рис. 3), образовались рефлексы $\mathrm{NiO}$ и $\mathrm{La}_{2} \mathrm{NiO}_{4}$, что говорит об укрупнении зерен данных фаз.

\section{4. Заключение}

Таким образом, структурные исследования композиции $\mathrm{PZT} / \mathrm{LNO} / \mathrm{Si}$ и пленок LNO методами просвечивающей электронной микроскопии позволяют сделать следующие выводы.

1) Слой LNO кристаллизуется с образованием мелкозернистой разориентированной пористой структуры с ярко выраженной слоистостью, обусловленной послойным методом нанесения пленкообразуещего раствора.

2) Разориентированная мелкокристаллическая структура LNO непосредственно влияет на структуру слоя PZT: наблюдается измельчение перовскитных зерен в сравнении с традиционными композициями на (111)ориентированной платине в 2-4 раза, хотя гетерогенный рост кристаллитов сохраняется.

3) Слоистость и пористость структуры LNO проявляются уже при температуре $550^{\circ} \mathrm{C}$, хотя при данной температуре еще наблюдается значительное количество аморфной фазы. Дальнейшее увеличение температуры приводит к укрупнению зерен от единиц нанометров при $550^{\circ} \mathrm{C}$ до $29.3 \pm 14.2 \mathrm{~nm}$ при $800^{\circ} \mathrm{C}$, слиянию пор и образованию трещиноподобных дефектов.

4) Слой LNO кристаллизуется с образованием многофазной системы, включающей $\mathrm{LaNiO}_{3}(P m \overline{3} m)$, $\mathrm{La}_{2} \mathrm{NiO}_{4}(I 4 / m m m), \mathrm{NiO}(F m 3 m), \mathrm{La}_{2} \mathrm{O}_{3}(P \overline{3} m 1)$, при этом заметен рост кристаллитов всех фаз при повышении температуры от 550 до $800^{\circ} \mathrm{C}$.

\section{Финансирование работы}

Исследование структуры образцов выполнено при финансовой поддержке Министерства науки и высшего образования в рамках выполнения работ по Государственному заданию ФНИЦ „Кристаллография и фотоника“ РАН. Работа выполнена с использованием оборудования ЦКП ФНИЦ „Кристаллография и фотоника“ РАН при поддержке Минобрнауки. Гетероструктуры 
синтезированы в федеральном государственном бюджетном образовательном учреждении высшего образования „МИРЭА - Российский технологический университет“ при частичной поддержке гранта РФФИ 19-29-03058.

\section{Конфликт интересов}

Конфликт интересов: авторы заявляют, что у них нет конфликта интересов.

\section{Список литературы}

[1] N. Setter, D. Damjanovic, L. Eng, G. Fox, S. Gevorgian, S. Hong, A.Kingon, H. Kohlstedt, N.Y.Park, G.B.Stephenson, I. Stolitchnov, A.K. Taganstev, D.V.Taylor, T.Yamada, S. Streiffer. J. Appl. Phys. 100, 051606 (2006).

[2] K.A. Vorotilov, A.S. Sigov. Phys.Solid State. 54, 894 (2012).

[3] M. Narayanan, S. Liu, B. Ma. Jpn. J. Appl. Phys. 52, 05DA10 (2013).

[4] А.В. Атанова, Д.Н. Хмеленин, О.М. Жигалина, Д.С. Серегин, К.А. Воротилов, А.С. Сигов. Наноматериалы и наноструктуры - XXI век 10, 29 (2019).

[5] Z. Duan, Y. Cui, Z. Yang, K. Li, Y. Wan, Z. Lu, X. Xie, J. Zhang. Ceram. Int. 44, 695 (2018).

[6] M.W. Zhu, Z.J. Wang, Y.N. Chen, Z.D. Zhang. J. Cryst. Growth. 336, 44 (2011).

[7] R.A.C. Amoresi, A.A. Felix, G.M.M.M. Lustosa, G. Gasparotto, A.Z. Simẽs, M.A. Zaghete. Ceram. Int. 42, 16242 (2016).

[8] T. Miyazaki, T. Imai, N. Wakiya, N. Sakamoto, D. Fu, H. Suzuki. Mater. Sci. Eng., B 173, 89 (2010).

[9] K. Vorotilov, A. Sigov, D. Seregin, Y. Podgorny, O. Zhigalina, D. Khmelenin. Phase Transit. 86, 1152 (2013).

Редактор Е.Ю. Флегонтова 